\title{
PEMILIHAN MODEL PREDIKSI INDEKS HARGA SAHAM \\ YANG DIKEMBANGKAN BERDASARKAN ALGORITMA SUPPORT VECTOR MACHINE(SVM) ATAU MULTILAYER PERCEPTRON(MLP) STUDI KASUS : SAHAM PT TELEKOMUNIKASI INDONESIA TBK
}

\author{
Rusma Insan Nurachim ${ }^{1}$ \\ Universitas Bina Sarana Informatika \\ Email: rusma.rsc@bsi.ac.id
}

\begin{abstract}
Abstrak
Dalam memprediksi suatu kondisi harga saham, beberapa model analisa teknik telah dipakai dan dikembangkan. Salah satunya dengan model data mining. Data mining merupakan salah satu cabang ilmu komputer yang mencakup database, kecerdasan buatan (artificial intelligence), statistik dan sebagainya. Penelitian ini melakukan analisis teknikal, yaitu diawali dengan mencari sifat multifraktal pada return saham objek penelitian dengan analisis rescaled range (untuk mendapatkan eksponen hurst) untuk mengetahui apakah data return tersebut bersifat acak atau terdapat pengulangan trend. Berikutnya akan dilakukan prediksi terhadap return saham tersebut dengan metode SVM (Support Vector Machines) dan MLP (Multilayer Perceptron) untuk kemudian akan dilakukan komparasi metode mana yang memiliki kesalahan lebih kecil dalam memprediksi indeks harga saham.

Kata kunci: data mining, saham, neural network, SVM, MLP
\end{abstract}

\begin{abstract}
In predicting a stock price condition, some models of analysis techniques have been used and developed. One of them with data mining models. Data mining is a branch of computer science that includes databases, artificial intelligence (artificial intelligence), statistics and so on. This study technical analysis, which begins with the search for the nature of the object multifraktal research on stock returns with rescaled range analysis (to get the hurst exponent) to determine if the return data is random or there is a repetition of the trend. Next will be a prediction of the stock return with the method of SVM (Support Vector Machines) and MLP (Multilayer Perceptron) to then be carried out comparative methods which have smaller errors in predicting stock price index.
\end{abstract}

Key words: data mining, stocks, neural network, SVM, $M L P$

\section{PENDAHULUAN}

Investasi saham merupakan salah satu investasi yang sangat menguntungkan, walaupun di sisi lain memiliki resiko yang sangat tinggi. Karena sifatnya yang sangat peka terhadap perubahan atau pun faktor lain yang mempengaruhinya, baik faktor internal maupun faktor eksternal perusahaan. Saham (stock) merupakan salah satu instrumen pasar keuangan yang paling popular. Saham dapat didefinisikan sebagai tanda penyertaan modal seseorang atau pihak (badan usaha) dalam suatu perusahaan atau perseroan terbatas [IDX 2010]. Berbagai cara ditempuh para investor dalam hal pengambilan keputusan investasi saham.

Hal lain yang berkaitan dengan permasalahan saham adalah prediksi harga saham. Dalam memprediksi suatu kondisi harga saham, beberapa model analisa teknik telah dipakai dan dikembangkan. Salah satunya dengan model data mining. Data mining merupakan salah satu cabang ilmu komputer yang mencakup database, kecerdasan buatan (artificial intelligence), statistik dan sebagainya. Definisi sederhana dari data mining adalah ekstraksi informasi atau pola yang penting atau menarik dari data yang ada di database yang besar. Dalam jurnal ilmiah, data mining juga dikenal dengan nama Knowledge Discovery in Databases (KDD).

Data mining memiliki banyak algoritma yang digunakan sebagai metode prediksi. Seperti metode prediksi rentet waktu yaitu Support Vector Machine (SVM), Neural Network (NN) dan Grey Model (GM) diusulkan oleh banyak peneliti [Huifei 2009]. Dari beberapa model tersebut, Neural Network (NN) memiliki kelebihan pada prediksi nonlinear, kuat di parallel processing dan kemampuan untuk mentoleransi kesalahan, tapi memiliki kelemahan pada perlunya data training yang besar, over-fitting, lambatnya konvergensi, dan sifatnya yang local optimum [Capparuccia 2007].

MLP (Multilayer Perceptron) merupakan salah satu metode dari Neural Network sangat cocok untuk menyelesaikan masalah yang tidak linear dan non deterministik [Umam, 2011]. MLP telah diterapkan dengan sukses untuk menyelesaikan masalah-masalah yang sulit dan beragam dengan melatihnya menggunakan algoritma propagasi balik dari kesalahan atau error backpropagation (EBP). Sedangkan kelebihan Support Vector Machine (SVM) adalah SVM tidak mengalami overfitting karena training perlu dilakukan sekali saja dan mendapatkan solusi optimal [Soelistyani 2013].

\section{LANDASAN PEMIKIRAN}




\section{Definisi Data Mining}

Data mining merupakan salah satu cabang ilmu komputer yang populer. Dan hingga saat ini masih ada orang yang memperdebatkan mengenai penempatan bidang ilmu untuk data mining. Karena data mining mencakup database, kecerdasan buatan (artificial intelligence), statistik dan sebagainya. Perkembangan data mining yang pesat tidak dapat lepas dari perkembangan teknologi informasi yang memungkinkan data dalam jumlah besar dan terakumulasi.

Menurut David Hand, Heikki Mannila dan Padharic Smyth dari MIT data mining adalah analisa terhadap data (biasanya data yang berukuran besar) untuk menemukan hubungan yang jelas serta menyimpulkannya yang belum diketahui sebelumnya dengan cara terkini dipahami dan berguna bagi pemilik data tersebut [Larose, 2006].

Data mining merupakan inti dari proses Knowledge Discovery in Database (KDD). KDD adalah proses terorganisir untuk mengidentifikasi pola yang valid, baru, berguna dan dapat dimengerti dari sebuah data set yang besar dan kompleks. Lebih lanjut mengenai KDD akan dijelaskan pada bagian selanjutnya.

\section{Pengertian Artificial Neural Network (Jaringan Syaraf Tiruan)}

Ada beberapa pengertian Artificial Neural Network (ANN) atau Jaringan Syaraf Tiruan (JST) menurut ahli, diantaranya:

1) Jaringan syaraf tiruan merupakan pemroses informasi yang memiliki karakteristik mirip dengan jaringan syaraf biologi ${ }^{[\text {Siang, 2005]. }}$

2) Jaringan syaraf tiruan adalah sebuah prosesor yang terdistribusi paralel, tersusun atas banyak unit pemrosesan yang sederhana, yang memiliki kecenderungan secara alamiah untuk menyimpan informasi dan menjadikannya siap untuk digunakan [Haykin, 1999].

3) Sistem syaraf tiruan atau jaringan syaraf tiruan adalah sistem selular fisik yang dapat memperoleh, menyimpan dan menggunakan pengetahuan yang didapat dari pengalaman [Sherrod, 2011].

Jaringan syaraf tiruan dibentuk sebagai generalisasi model matematika dari jaringan syaraf biologi ${ }^{[S i a n g,}{ }^{2005]}$ dengan asumsi sebagai berikut:

1) Pemrosesan informasi terjadi pada banyak elemen sederhana (neuron).

2) Sinyal dikirimkan diantara neuron melalui penghubung.

3) Penghubung antar neuron memiliki bobot yang akan memperkuat atau memperlemah sinyal.

4) Untuk menentukan keluaran (output), setiap neuron menggunakan fungsi aktivasi yang dikenakan pada penjumlahan masukan (input) yang diterima. Besarnya keluaran (output) ini selanjutnya dibandingkan dengan suatu batas ambang.

Neuron adalah unit pemroses informasi yang menjadi dasar dalam pengoperasian jaringan

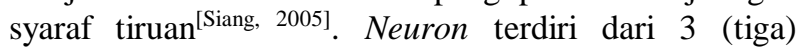
elemen pembentuk sebagai berikut:
1) Himpunan unit-unit yang dihubungkan dengan jalur koneksi.
2) Suatu unit penjumlah yang akan menjumlahkan masukan-masukan sinyal yang sudah dikalikan dengan bobotnya.
3) Fungsi aktivasi yang akan menentukan apakah sinyal dari input neuron akan diteruskan ke neuron lain ataukah tidak.
Jaringan syaraf tiruan ditentukan oleh 3 (tiga) hal sebagai berikut:
1) Pola hubungan antar neuron (arsitektur jaringan).
2) Metode untuk menentukan bobot penghubung (algoritma training/learning/pelatihan/belajar).

3) Fungsi aktivasi.

Di dalam jaringan syaraf tiruan, istilah simpul (node) sering digunakan untuk menggantikan neuron.

\section{Multilayer Perceptron (MLP)}

Jaringan syaraf adalah model prediksi yang didasarkan pada tindakan neuron biologis. Sebuah jaringan syaraf khas buatan mungkin memiliki seratus neuron. Sebagai perbandingan, sistem syaraf manusia diyakini memiliki sekitar $3 \times 10^{10}$ neuron.

Model Perceptron dikembangkan oleh Frank Rosenbalt pada tahun 1958. Model Rosenbalt terdiri dari tiga lapisan meliputi:

1) Sebuah "retina" bahwa input didistribusikan ke lapisan kedua,

2) "Asosiasi unit" yang menggabungkan input dengan bobot dan memicu fungsi ambang langkah yang mengumpan ke lapisan output,

3) Lapisan output yang menggabungkan nilainilai.

Sayangnya, penggunaan fungsi langkah dalam neuron membuat persepsi yang sulit atau tidak mungkin untuk melatih. Sebuah analisis kritis perceptron diterbitkan pada tahun 1969 oleh Marvin Minsky dan Papert Seymore menunjukkan sejumlah kelemahan kritis perceptron dan untuk beberapa waktu, minat terhadap perceptron berkurang.

"Bunga" dalam jaringan syaraf dihidupkan kembali pada 1986 ketika David Rumelhart, Geoffrey Hinton dan Ronald Williams diterbitkan "Belajar Representas Internal dengan Propagasi Error". Mereka mengusulkan jaringan syaraf multilayer dengan fungsi transfer 
terdeferensialkan nonlinier tetapi yang menghindari perangkap fungsi langkah perceptron yang asli. Mereka juga memberikan algoritma pelatihan cukup efektif untuk jaringan syaraf.

Istilah Neural Network (NN) dan Jaringan Syaraf Tiruan (JST) biasanya merujuk ke Jaringan Perceptron Multilayer. Namun ada banyak jenis jaringan syaraf termasuk Probabilistic Neural Networks, General Regression Neural Networks, Radial Basis Function Networks, Cascade Correlation, Functional Link Networks, Kohonen, Gram-Charlier Networks, Learning Vector Quantization, Hebb, Adaline, Heteroassociative, Recurrent dan Hybrid.

Diagram berikut menggambarkan jaringan perceptron dengan tiga lapisan:

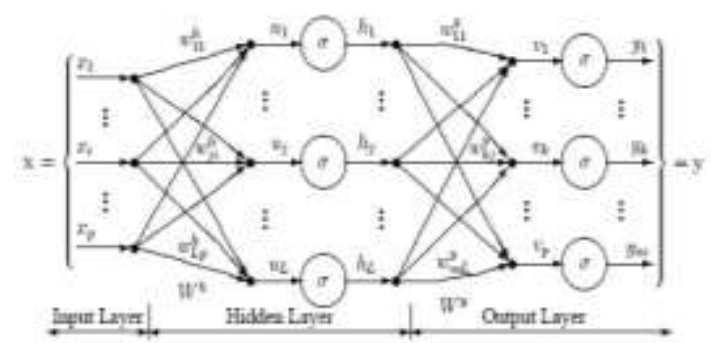

Gambar 1. Jaringan Perceptron 3 Lapisan [Sherrod 2011]

Pada gambar diatas memiliki lapisan input (di sebelah kiri) dengan ketiga neuron, satu lapisan tersembunyi (di tengah) dengan tiga neuron dan lapisan output (sebelah kanan) dengan tiga neuron.

Ada satu neuron pada lapisan masukan untuk setiap variabel prediktor. Dalam kasus variabel kategori, N-1 neuron digunakan untuk mewakili kategori $\mathrm{N}$ variabel.

Lapisan-lapisan pada Multilayer Perceptron adalah sebagai berikut:

1) Lapisan Input (input layer)

Sebuah vektor dari nilai-nilai variabel prediktor $\left(\begin{array}{lll}x_{1} & \ldots & x_{p}\end{array}\right)$ disajikan ke lapisan input. Lapisan input (pengolahan sebelum input layer) standarisasi nilai-nilai ini sehingga rentang dari setiap variabel adalah -1 ke 1. Lapisan masukan mendistribusikan nilai-nilai untuk setiap neuron pada lapisan tersembunyi. Selain variabel prediktor, ada masukan konstan sebesar 1,0 yang disebut bias yang diumpankan ke masing-masing lapisan tersembunyi, bias dikalikan dengan berat dan ditambahkan ke jumlah masuk ke neuron.

2) Lapisan tersembunyi (hidden layer)

Tiba di neuron pada lapisan tersembunyi, nilai dari setiap neuron input dikalikan dengan bobot $\left(\begin{array}{ll}w & j i\end{array}\right)$ dan nilai-nilai tertimbang yang dihasilkan ditambahkan bersama-sama menghasilkan nilai gabungan $u j$. Jumlah tertimbang $\left(\begin{array}{ll}u & j\end{array}\right)$ dimasukkan ke fungsi transfer, (omega) yang output $h j$. Keluaran dari lapisan tersembunyi didistribusikan ke lapisan output.

3) Lapisan Keluaran (output layer)
Tiba di neuron pada lapisan output, nilai dari setiap neuron lapisan tersembunyi dikalikan dengan bobot $\left(\begin{array}{ll}w & \mathrm{kj}\end{array}\right)$ dan nilai-nilai tertimbang yang dihasilkan ditambahkan bersama-sama menghasilkan nilai gabungan $v \quad j$. Jumlah tertimbang $\left(\begin{array}{ll}v & j\end{array}\right)$ dimasukkan ke fungsi transfer (omega) yang output nilai $y \quad k$. Nilai-nilai y adalah output dari jaringan. Jika analisis regresi yang dilakukan dengan variabel sasaran terus menerus, maka ada neuron tunggal pada lapisan output dan menghasilkan nilai y tunggal. Untuk masalah klasifikasi dengan variabel target kategoris, ada neuron $\mathrm{N}$ dalam lapisan output memproduksi nilai-nilai-N, satu untuk setiap kategori $\mathrm{N}$ dari variabel target.

Tujuan dari proses pelatihan adalah untuk menemukan set nilai berat yang akan menyebabkan output dari jaringan syaraf agar sesuai dengan nilai-nilai target yang sebenarnya sedekat mungkin. Ada beberapa isu yang terlibat dalam merancang dan melatih jaringan multilayer perceptron:

1) Memilih berapa banyak lapisan tersembunyi untuk digunakan dalam jaringan.

2) Memutuskan berapa banyak neuron untuk digunakan dalam setiap lapisan tersembunyi.

3) Mencari solusi optimal global yang menghindari minimum lokal.

4) Konvergen ke solusi optimal dalam jangka waktu yang wajar.

5) Memvalidasi jaringan syaraf untuk menguji overfitting.

\section{Support Vector Machine}

Support Vektor Machine (SVM) merupakan metode klasifikasi jenis terpadu (supervised) karena ketika proses pelatihan, diperlukan target pembelajaran tertentu[Prabowo, 2013]

SVM muncul pertama kali pada tahun 1992 oleh Vladimir Vapnik bersama rekannya Bernhard Boser dan Isabelle Guyon. Dasar untuk SVM sudah ada sejak tahun 1960-an (termasuk karya awal oleh Vapnik dan Alexei Chervonenkis pada teori belajar statistik).

Meskipun waktu pelatihan SVM kebanyakan lambat, tetapi metode ini sangat akurat karena kemampuannya untuk menangani model-model nonlinear yang kompleks. SVM kurang rentan terhadap overfitting dibandingkan metode lainnya. SVM dapat digunakan untuk prediksi dan klasifikasi. Contoh penerapannya antara lain deteksi tulisan tangan, pengenalan obyek, identifikasi suara dan lain-lain.

Dalam bahasa literarur SVM, variabel prediktor disebut atribut dan atribut berubah yang digunakan untuk menentukan hyperplane disebut fitur. Tugas memilih representasi paling cocok dikenal sebagai seleksi fitur. Satu set fitur yang menggambarkan satu kasus (misalnya deretan nilai prediktor) disebut vektor. Jadi tujuan dari pemodelan SVM adalah untuk 
menemukan hyperplane optimal yang memisahkan cluster dari vektor sedemikian rupa sehingga kasus dengan satu kategori dari variabel target yang berada pada satu sisi dari bidang kasus dengan kategori lainnya adalah pada ukuran lain dari pesawat. Vektor-vektor dekat hyperplane tersebut adalah vektor-vektor dukungan. Berikut gambar dari proses SVM.

\section{Tabel 1. Ringkasan Tinjauan Studi}

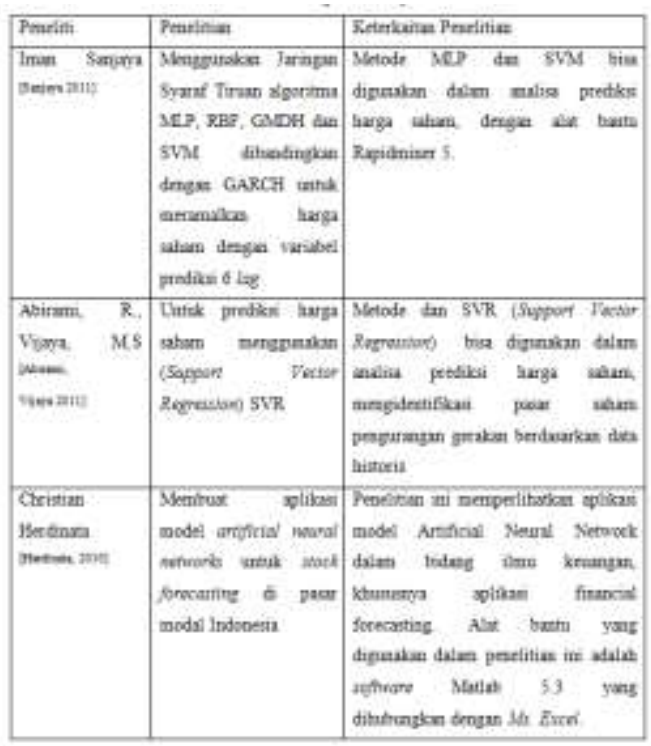

Perbedaan dengan penelitian sebelumnya adalah:

a. Peneliti Iman Sanjaya menggunakan beberapa metode yang dibandingkan untuk mendapat hasil prediksi dengan variabel prediksi 6 lag, sedangkan penelitian ini menambahkan variabel prediksi 10 lag untuk mendapatkan hasil yang lebih baik.

b. Peneliti Abirami menggunakan metode Support Vector Regression sedangkan penelitian ini menggunakan MLP dan SVM.

Peneliti Herdinata menggunakan tool berupa software

Matlab 5.3 yang dihubungkan dengan Ms. Excel

sedangkan penelitian ini menggunakan software

Rapidminer 5.

\subsection{Kerangka Pemikiran}

Kerangka pemikiran dari penelitian ini terdiri dari beberapa tahap seperti dengan permasalahan pada penelitian ini adalah belum diketahui algoritma yang akurat untuk meprediksi indeks harga saham PT Telekomunikasi Indonesia, Tbk. Untuk itu dibuat model pendekatan dengan menggunakan algoritma Multilayer Perceptron (MLP) dan Suppor Vector Machine (SVM), untuk memecahkan permasalahan kemudian dilakukan pengujian terhadap kinerja dari kedua metode tersebut. Kerangka pemikiran dalam penelitian ini dapat dilihat pada gambar berikut:

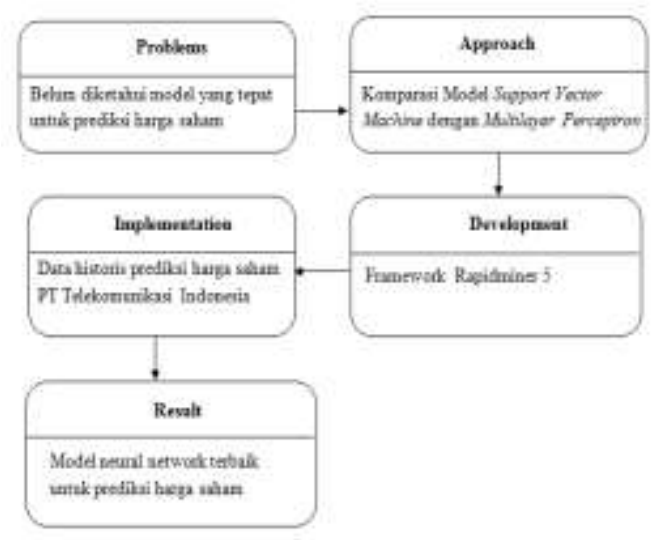

Gambar 2. Kerangka Pemikiran

\section{Metode dan Rancangan Penelitian \\ Teknik Analisis dan Pengumpulan Data}

Dalam Penelitian ini, data yang telah diperoleh yaitu berupa harga saham akan dibagi menjadi data training dan data validasi. Data training dan data validasi diproses dengan metode Jaringan Syaraf Tiruan, model Multi layer Perceptron (MLP) dan Support Vector Machine (SVM) yang dimainkan dengan Support Vector Regression (SVR). Variabel prediksi akan dibedakan dalam dua model, yaitu 6 lag dan 10 lag. Balkin [Balkin, 2000] merekomendasikan jumlah lag pada Neural Network untuk prediksi data harian adalah lag 1 sampai dengan lag 6. Namun dalam eksperimen ini tidak menggunakan variabel lag. Data diproses menggunakan Rapidminer 5 kemudian hasil pemrosesan data mining akan dianalisa, dengan membandingkan tingkat Error dari pemrosesan data validasi terhadap algoritma Multi layer Perceptron (MLP) dan Support Vector Regression (SVR) pada masing-masing model prediksi. Tingkat Error yang digunakan berupa: Maximum Error (ME), Root Mean Squared Error (RMSE), Mean Squared Error (MSE), Mean Absolute Error (MAE), dan Mean Absolute Percentage Error (MAPE). Keputusan ditekankan pada nilai Root Mean Squared Error (RMSE). Setelah itu hasil dari eksperimen model prediksi akan dibandingkan. Algoritma dengan tingkat Error terkecil adalah algoritma yang dianggap paling akurat.

\section{Langkah-langkah Penelitian}




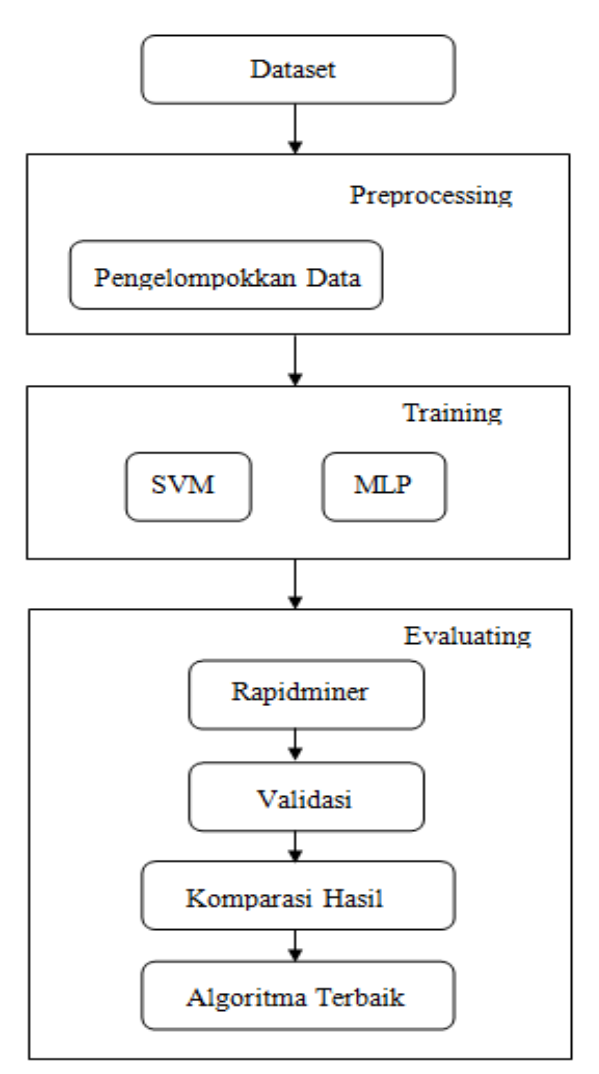

Gambar 3. Langkah-langkah Penelitian

Pada langkah-langkah penelitian diatas dapat dijelaskan sebagai berikut:

1. Data mentah diolah terlebih dahulu kemudian dipisahkan menjadi dua yaitu data training dan data testing.

2. Data yang sudah diolah kemudian diuji dengan algoritma SVM dan MLP.

Dengan bantuan tools software Rapidminer data tersebut divalidasi dan dibandingkan hasilnya hingga didapatkan algoritma terbaik.

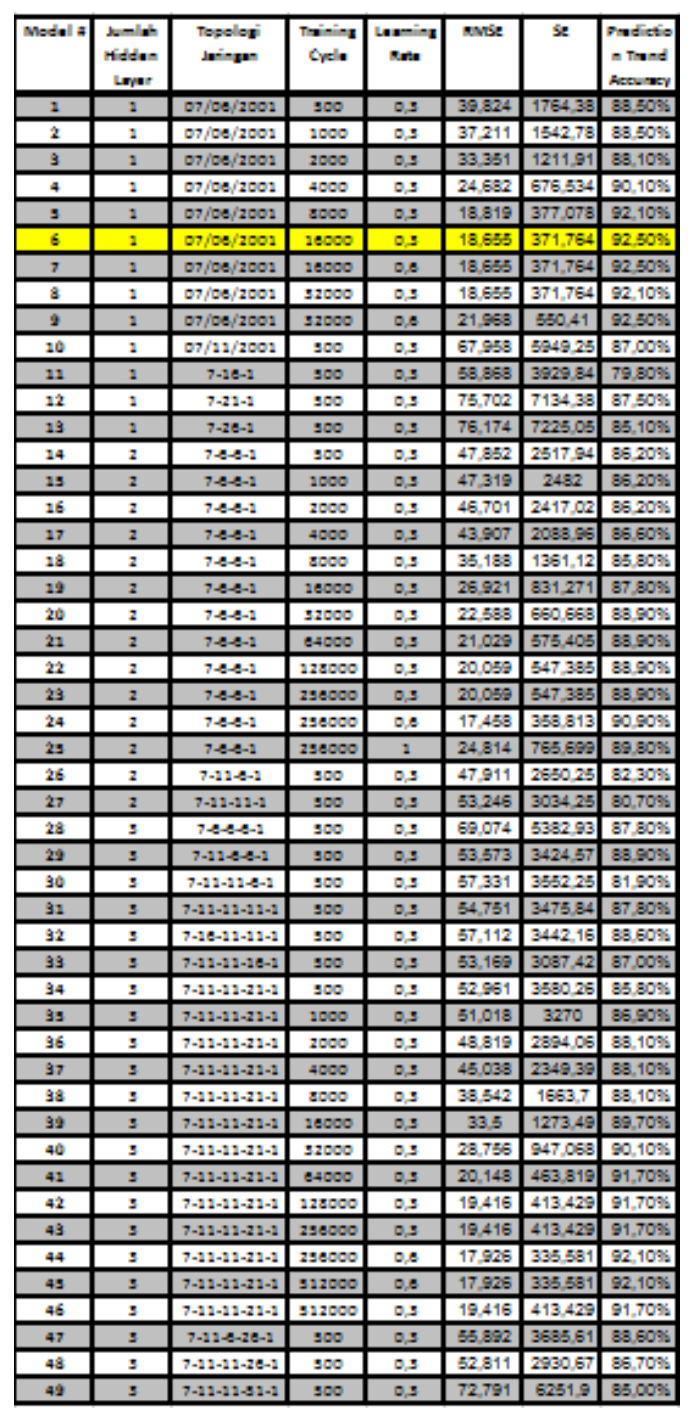

Tabel 3. Hasil MLP

Hasil Eksperimen

Multilayer Perceptron (MLP)

Support Vector Machine (SVM) 


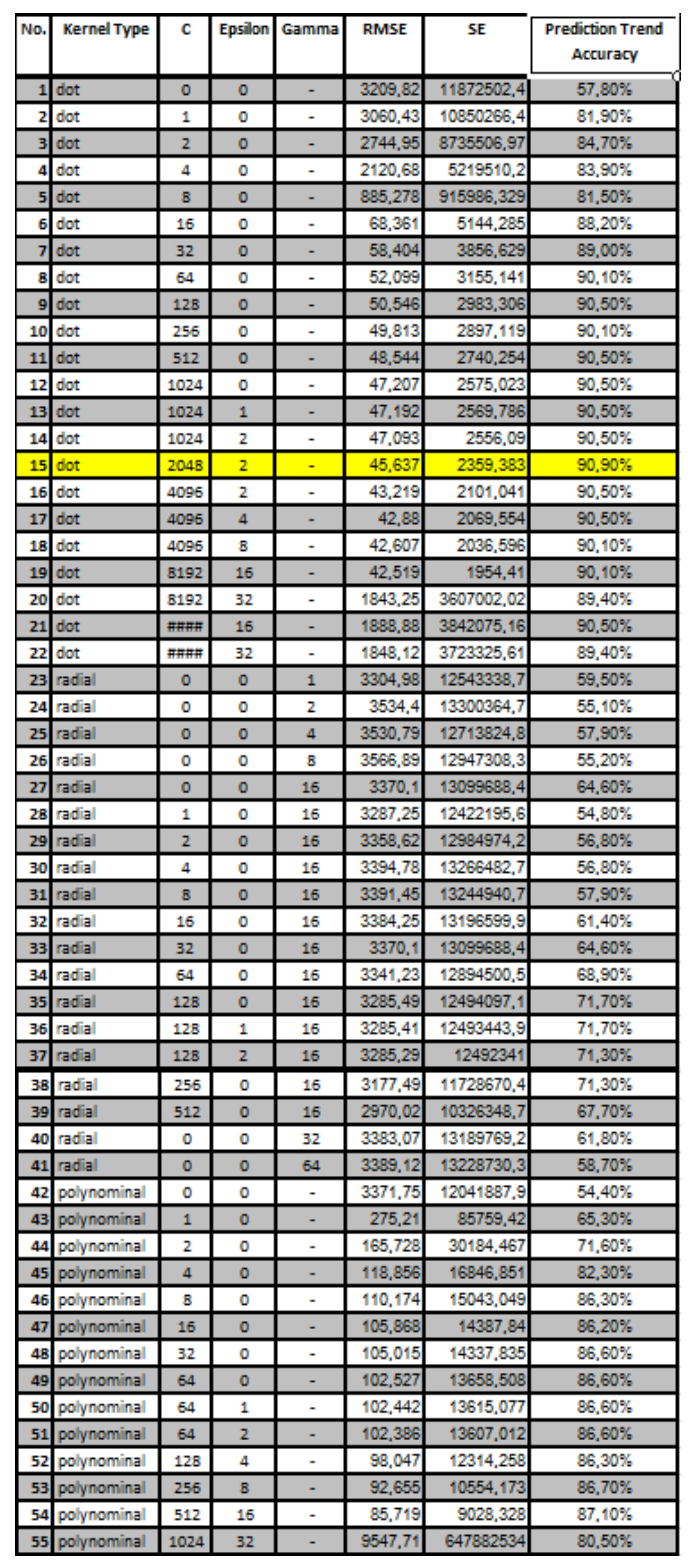

Tabel 4. Hasil SVM

\section{Komparasi Hasil Prediksi}

Dari hasil yang ditampilkan dalam tabel pada poin sebelumnya, dapat dilihat perbandingan dari setiap model. Pada tabel SVM eksperimen dengan hasil prediksi tertinggi terdapat pada ekspreimen ke 15 dengan hasil 90,9\%. Sedangkan pada tabel MLP terdapat pada eksperimen ke 6 dengan akurasi hasil prediksi yang lebih tinggi dari model SVM yaitu mencapai $92,5 \%$.

\section{PENUTUP}

Kesimpulan yang yang dapat ditarik dari penelitian ini adalah penelitian ini dilakukan untuk merancang perbandingan dua model algoritma yaitu Multilayer Perceptron (MLP) dan Support Vector Machines (SVM) yang diharapkan dapat memunculkan algoritma terbaik yang dapat meramalkan/memprediksi indeks harga saham. Eksperimen dilakukan beberapa kali untuk mendapatkan hasil terbaik.

Dan kesimpulan yang dapat diambil dari penelitian ini adalah:

1. Algoritma Multilayer Perceptron (MLP) dan algoritma Support Vector Machine (SVM) dapat diterapkan untuk memprediksi harga saham.

Dari hasil eksperimen ditemukan bahwa algoritma Multilayer Perceptron (MLP) menunjukkan tingkat akurasi prediksi yang lebih tinggi dibanding algoritma Support Vector Machine (SVM).

\section{Daftar Pustaka}

Abirami, Vijaya (2011) Abirami, R., \& Vijaya, M. S. (2011, December). An Incremental Learning Approach for Stock Price Prediction Using Support Vector Regression. International Journal of Research and Reviews in Artificial intelligence (IJRRAI) Vol. 1, No. 4, 81-85.

Capparucia (2007) Capparuccia, R., Leone , R. D., \& Marchitto, E. (2007, July 5). Integrating support vector machines and neural networks. Journal Neural Networks, 20(5), 590-597.

Esfahanipour, Aghamiri (2012) Esfahanipour, A., \& Aghamiri, W. (2012, July). Adapted NeuroFuzzy Inference System on indirect approach TSK fuzzy rule base for stock market analysis. Journal Expert Systems with Applications: An International Journal, 37(7), 4742-4748.

Fariza, Rasyid (2007) Fariza, A., Helen, A., \& Rasyid, A. (2007). PERFORMANSI NEURO FUZZY UNTUK PERAMALAN DATA TIME SERIES. Seminar Nasional Aplikasi Teknologi Informasi 2007 (SNATI 2007), (hal. 77-82). Yogyakarta.

Gorunescu, (2011) Gorunescu, F. (2011). Data Mining Concept Model Technique: Intelligent Systems Reference Library,Volume 12. Verlag Berlin Heidelberg: Springer.

Herdinata, (2010) Herdinata, Christian (2010). Aplikasi Model Artificial Neural Networks Untuk Stock Forecasting Di Pasar Modal Indonesia. Jurnal Keuangan dan Perbankan Vol 14, hal 1-12

Hidayat, (2012) Hidayat, Taufik (2012). Pemilihan Model Prakiraan Cuaca Berbasis Neural Network: Studi Kasus Badan Meteorologi Klimatologi dan Geofisika (BMKG) Jakarta. Tesis

IDX, (2010) IDX. (2010). Indonesia Stock Exchange. Dipetik Mei 6, 2013, dari IDX Indonesia 
Stock Exchange Bursa Efek Indonesia: http://www.idx.co.id/idid/beranda/informasi/bagi investor/saham.aspx

Kusrini, Luthfi (2008) Kusrini , \& Luthfi, E. T. (2008). Algoritma Data Mining. Yogyakarta: Andi Publishing.

Maimon, (2010) Maimon, O., \& Rokach, L. (2010). Data Mining and Knowledge Discovery Handbook; Second Edition. New York : Springer

Muhtaram, (2011) Muhtaram, A. (2011). Pengertian Data Mining dan Konsep Data Mining. Dipetik

Mei 18, 2013, dari Metris Comunity: http://www.metriscommunity.com/pengertiandata-mining-konsep-pdf/

Riadi, (2012) Riadi, M. (2012, Desember 24). Pengertian dan Jenis-Jenis Saham. Dipetik Mei 16, 2013, dari Kajian Pustaka: http://www.kajianpustaka.com/2012/12/pengertia n-dan-jenisjenissaham.html\#.UaZWzKLrzzw

Saaty, (2008) Saaty, T. L. (2008). Decision making with the analytic hierarchy process. Int. J. Services Sciences,, Vol I, No.1, 83-98.

Umam, (2011) Umam, A. (2011). Metode Jaringan Syaraf Tiruan: Multilayer Perceptron. Dipetik
Juni 27, 2013,

http://ardianumam.web.ugm.ac.id/:

http://ardianumam.web.ugm.ac.id/?p=399

Vercellis, (2009) Vercellis, C. (2009). Business Intelligence: Data Mining and Optimization for Decision Making. Cornwall: Wiley.

Wahono, (2012) Wahono, R. S. (2012, 06 18). Kiat Menyusun Alur Latar Belakang Masalah Penelitian. Dipetik 02 13, 2013, dari http://romisatriawahono.net/: http://romisatriawahono.net/2012/06/18/kiatmenyusun-alur-latarbelakang-masalahpenelitian/

Wahono, (2012) Wahono, R. S. (2012, 08 07). Kiat Menyusun Kerangka Pemikiran Penelitian.

Dipetik 05 27, 2013, dari http://romisatriawahono.net:

http://romisatriawahono.net/2012/08/07/kiat -menyusun-kerangkapemikiran-penelitian/

Wibowo, Mardiyanto (2011) Wibowo, A., \& Mardiyanto, S. (2011). Penerapan Metode Adaptive-NetworkBased Fuzzy Inference System (ANFIS) Model Sugeno Untuk Memprediksi Index Saham.

Wu, Kumar (2009) Wu, X., \& Kumar, V. (2009). The Top Ten Algorithms in Data Mining. New York: CRC Press. 